\title{
The Language of Advertising in English Sport Magazines
}

\author{
Gevorg Barseghyan \\ Yerevan State University
}

\begin{abstract}
Advertising plays a crucial role in our reality. It invades our lives through TV screens, radio frequencies, the pages of newspapers and journals. Being a unique phenomenon in our reality, which is designed for thousands of readers, listeners, viewers, it has given birth to different approaches and opinions. Advertising is a rapidly developing phenomenon, quick in responding to major and minor changes in the social life. Today it has penetrated into sports as well. Sport is a big business and many companies use sport as a means of publicizing their product. Thus, the present paper intends to study sport ads with the aim of presenting them as a register standing out for uniqueness, containing a small scale plot which aims to draw the attention of the reader to the phenomenon. Usually such small texts use the names of world famous sportsmen which immediately attract attention. In sport ads the plot usually includes certain qualities which demonstrate the skills of a given sportsman, and the object is advertised through creating a text which is combined with illustrations of the very object.
\end{abstract}

Key words: sports language, sports print advertisements, expressive means, stylistic devices, celebrated sportsman, illustrations.

\section{Introduction}

Despite the fact that thousands of various scientific studies have been carried out in the last hundred years, there is no generally accepted specific approach or formulation clarifying the true nature of advertising. The creation of good advertising is as hard and complicated as that of a piece of art although 
advertising is not only art but also creation of an informative text with the addition of images which, in their turn, impact the reader/viewer and render certain information.

Bill Bernbach, the founder of "Doyle, Den and Bernbach", says that it is not important what you do. All that counts is how you do it. "The basis of good advertising is understanding human behavior and respecting it" (Clark 1988:416).

Good advertising should contain at least a particle of psychology, linguistics, sociology, economics, i.e. nearly of all professions and arts. There is much research of ads, especially research of advertising in press which focuses on language and style (Antin 1993:247), while the language of sport journals and magazines and the language of ads in particular have not yet undergone a thorough linguistic investigation.

Sport ads or, to be more exact, ads in English sport magazines tend to present a unique form of writing containing a small scale plot which aims to draw the attention of the reader to the object or phenomenon. Usually such small texts use the names of world famous sportsmen which immediately attract attention. In sport ads the plot includes certain qualities and may demonstrate the skills of a given sportsman. The object is advertised through creating a text combined with illustrations of the very object.

\section{Some Notions on Advertising}

The most important feature of advertising, which has lived through centuries, is the statement providing some information about a certain topic. It forms an opinion and eventually prompts to use certain services, to participate in a certain event or simply take up some sports. The text of the advertising retains the language norm. It is the application of regulated, commonly accepted, legalized linguistic means and forms. The language norm is related to all levels of the language. Its violation in written speech is more frequently expressed on stylistic and syntactical levels, i.e. in the choice of words, and in the creation of syntactic structures.

In general, most diverse principles have been advanced for the 
classification of advertisements. Advertising can be divided into three main groups - visual, auditory and visual-auditory. The first group is more common and is realized by the combination of photos, light effects and speech. Auditory advertising is carried out through radio or oral speech. The third group comprises TV commercials, movie commercials where the display is coupled with a text or may be presented without it. Printed advertisements can have different expressions - a poster, a notification, a calendar, an album, a booklet, an ads pamphlet, a price list, a label, etc. Newspaper advertising is of special interest. It stands out with its rapid reaction. Unlike others, it is more economical and is more efficient in its delivery. Obviously, advertising is more influential and impressive when published in a prestigious journal.

\section{Advertising in Sport Magazines}

In order to turn to the reflection of sports language in business, I would like to present it in the light of sports print advertisements in English sport journals and magazines. The language of sport advertising is in constant development. If the expressive means are weak, the advertising gets less persuasive. Hence, it is important to find out what stylistic devices are used by the reporters when making texts of sport advertisements.

Very often the name of a celebrated sportsman or of a representative of a well-known company is used to make the text more attractive. With the help of a small plot which usually stands out with the quick pace of events, the reporter makes sharp switches to the desired topic - the advertising of sports shoes, for example, designed by modern technology - stands out with a completely new structure.

Adi Dassler watched from the sideline as Germany beat the heavily fovoured Hungarians on a waterlogged pitch in the World Cup final. His latest innovation, the weltmelster boot with interchangeable studs for any condition, changed Germany's fortune. And football forever.

(The History of FIFA, 2004:44) 
Obviously, the use of the different meanings of the same expression helps make advertising more impressive and the text more interesting both in its delivery form and its content. Advertising weltmelster boot with interchangeable studs for any condition works well through a stylistic device, i.e. the hyperbole (changed Germany's fortune).

Very often sport advertising makes use of plots of short length which aim to center the attention of the reader on the phenomenon. If the aim of the advertising is presented at the very beginning, it will be exhausted and will lose the power of effect. Hence, the text of advertising is constructed so that the intention and the purpose are not evident right from the outset. Usually, short texts use the names of world-famous sportsmen who immediately draw the attention of the public.

Zidane laces up the predator every day. With its weight balanced toward the foot, the new power pulse technology puts maximum power behind all of his shots. And the asymmetric lacing provides a smooth striking surface for his precise passes and finishes that leave fans and goals in tension. Impossible is nothing.

(FIFA magazine, March 2004:44)

The above ad on Adidas sport shoes makes a reference to Zidane who fastens the laces of his sport shoes every day (Zidane laces up the predator every day). The next sentence enhances the professional quality of the sportsman who has developed the strength of his kick to maximum accuracy the (new power pulse technology puts maximum power behind all of his shots). The third and also the last sentence somehow sum up the ideas stated, thus enhancing the advantages of the sport shoes. The expression asymmetric lacing places the text of the advertising into a certain structure and links it with the first sentence. However, the last sentence unexpectedly brings a new color to the object advertised, in this case the Adidas sport shoes. The asymmetric lacing provides a smooth striking surface which helps the precise passes of the sportsman. The 
final genuine metaphor comes to prove that impossible is nothing. In other words, nothing is impossible for Zidane as well as for the company Adidas that produces sports shoes. It also acts as a general conclusion to the text and might as well have served as a good headline.

Sport advertising whose plot includes the qualities of a given sportsman and the object advertised, thus creates a complete text, coupled with some illustrations of the advertised object.

Let us consider another ad with typical characteristics.

What every handball player needs.

"Better feet"

Jackson Richardson

National French handball team

Feet wear shoes are based on the greatest piece of sports equipment ever. The wraparound midsole and rounded edges give more stability and agility. Just ask Jackson Richardson if you can grab hold of him for a min... too late, he's passed you'.

(WORLD HANDBALL magazine, 4/97: 8)

The first utterance immediately centers the attention of the reader on the reply although it is not an interrogative sentence. Each professional handball sportsman needs high-quality sport shoes. Both utterances belong to J. Richardson, a member of the French National Handball Team. However, the text of the ad is constructed not with the collective use of the direct speech and authorial speech, as is done usually. Rather, the inquiry and the answer are presented with separate sentences. The second sentence is a nominal impersonal sentence (Better feet) and makes the speech concise. There is no authorial speech between the direct speech and its author. The reader is simply given the name and surname of the celebrated player in the French National Handball team.

This initial information is combined with illustrations showing the 
dynamism of the forward which is followed with the text itself. The ad focuses on the qualities of the given object which helps the object differ from many similar ones. Moreover, the text in the ad is constructed in such a way that the qualities of the sport shoes have their direct "impact" on the trainings and matches. They ensure stability and agility due to the wraparound midsole and rounded edges.

To make a sport ad more impressive the texts that make both graphs and photos are presented in diverse fonts. This avails the possibility of making the given ad more expressive, to achieve a deeper insight into the topic of the ad and finally attract public attention.

In certain cases, the advertised object is not presented with any feature or description. In this case the text of the ad stands out with its unusual and comprehensive information. To attract attention - this is what counts here. The rest is filled with imagination as well as with the combination of photos.

\section{SSK. Building Legends around the World. Baseball outfit.}

(World baseball, N3/1995:2)

Introducing the baseball outfit (a ball, sport shoes, gloves, etc.) in only one utterance helps the reader get a certain idea about the reputation of the given company, the unlimited quantity of the exports of the goods, as well as of the high quality of the object.

Such a structure of the content of the ad text is generally applied in the advertisement of baseball kits. Combining the text of only one utterance and with photos of various baseball kits, creates the impression that the outcome of the match is considerably dependent on the high quality outfit of the given company $(S S K)$. In general, an ad text can actually be made up of only one utterance - the nominal impersonal sentence.

The ad of the Sports Flooring of Handball is structured as follows: 


\section{Champions have chosen Taraflex Sports Flooring to realize the best performance and give you the greatest emotions. \\ Excellent sporting characteristics, comfort, shock absorption... as many assets that bring Gerflor to the top at World competitions.}

(WORLD HANDBALL magazine, 3/2001:2)

The first sentence contains general information about Taraflex Sports Flooring. The technique here is not to use a famous single name but the collective word champions which is a "call" addressed to all sportsmen who want to become champions. On the way to this aim they will choose Taraflex Sports Flooring to be able to realize the best performance and give you the greatest emotions. The sentence also has another aim - to center the attention of the reader on the product of the given company.

The second utterance enumerates the qualities of the object advertised excellent characteristics, comfort, shock absorption. The mentioned qualities make the given company and its products number one in the world chart.

Now, let us consider a number of ads where the application of adjectives and stylistic devices further enhances the impact of the ad. At large, the cases of adjective use are abundant, especially in comparative and superlative degrees. This is natural since adjectives contain qualities which are exceptional, and excel other parts of speech when describing phenomena and objects. The superlative degree of adjectives is frequently used in the following ads which refer not only to sports but also to companies that sponsor a certain sporting event.

McDonald's, proud sponsor of the world's biggest soccer game, even prouder sponsor of some of the world's smallest.

(FIFA magazine, June 2003:4) 
One of the world's fastest growing airlines, has united with one of the world's most exciting events.

Emirates Airlines

(FIFA magazine, June 2003:14)

ISL brings a new professionalism to the marketing of sports federation properties, uniting international companies with the world's greatest sports events in a constructive partnership.

(SporTVision, No121, January 1998:8)

The simile is used to make an ad imaginative and expressive, thus impacting the reader emotionally.

The adidas shoes are slight and rapid like a falcon.

(Swiss Futsal Magazine, 2004:9)

The usage of hyperbole is a typical characteristic of a sport ad.

We might be at home

The world over,

But soon we'll be welcoming

The World to our home.

Proud sponsors of World Cup 2006

German tires Continental

(FIFA magazine, January 2004:74)

Sport ads frequently make use of personification when human features are attributed to things and phenomena.

Children's football enters your house.

(FIFA magazine, March 2004:38) 


\section{FIFA is always ahead.}

(CHAMPIONS, December/January 2004:55)

The application of colloquial words is also quite frequent in sport ads because colloquial words are very productive in creating a friendly mood and atmosphere.

Excellent, slight, unslip, yes, even the measures are not large.

Basketball ball

(Basketball Promotion NEWS, 1/99:43)

As already mentioned, sport ads make abundant use of names and opinions of well-known sportsmen or they simply state that the sportsman uses the product of the given organization.

Zidane laces up the predator every day....

Sports shoes

(FIFA magazine, March 2004:44)

"Your production is hopeful" says Jackson Richardson.

Sports shoes

(WORLD HANDBALL magazine, 4/97:8)

Antonyms are used to make an impressive speech. They help to emphasize the features and characteristics of the product advertised.

New-fashioned look not to modern sports shoes.

(FIFA magazine, March 2004:44)

Minimum time - maximum business.

Emirates Airlines

(FIFA magazine, January 2004:67) 
Parallel constructions and repetition are quite abundant in sports ads, i.e. the same syntactical construction is repeated in succeeding sentences.

You will gain

sport will gain.

Everlast boxing gloves

(BOXING 1999, N35:14)

Below is another example of repetition in a sport ad. This stylistic device possesses a great semantic value. It intensifies the emotive content, the rhythm, musicality of the speech.

More power.

More control.

More effect.

Adidas shoes

(Soccer 1994:2)

In the above example the repetition of the word more and the parallel constructions create certainty through rhythm, make what is said more impressive and emphasize the advantages of the advertised product.

\section{Conclusion}

The analysis undertaken in the present paper comes to confirm the idea that advertising and especially sports advertising finds its true expression by means of language in the first place, though the role of non-linguistic elements in the realization of an ad purpose cannot be underestimated, either. Language is the most important constituent in an ad since it bears the main burden of conveying a message to the consumers, persuading and making an influence on them. The role of linguistic "instruments" and stylistic devices make sport advertisements in magazines more attractive and unique. Thus, in a sport ad the question-answer is expressed with a nominal impersonal sentence which makes the speech more concise (1); to make the sport ad more impressive, the text-accompanying graphs and photos are of different fonts (2); the use of adjectives in sports ads is quite 
frequent, particularly adjectives in comparative and superlative degrees (3); simile, hyperbole, personification, lexical contrast, parallel constructions are used to create an image for sport ads (4); names and opinions of various worldacclaimed sportsmen are used abundently to give credibility to the ad (5).

\section{References:}

1. Antin, T. (1993) Great Print Advertising: Creative Approaches, Strategies and Tactics. New York: J. Wiley.

2. Clark, E. (1988) The Want Makers: The World of Advertising: How They Make You Buy. New York: Viking.

3. Leech, G.N. (1966) English in Advertising. A Linguistic Study of Advertising in Britain. London: Longman.

4. Rozental, D.; Kokhtev, N. (1981) Yazik reklamnikh tekstov. Moskva: Visshaya Shkola.

\section{Sources of Data:}

1. Basketball Promotion NEWS 1/99.

2. BOXING 1999, N35.

3. CHAMPIONS, December/January 2004.

4. FIFA magazine, June 2003, January 2004, March 2004.

5. The history of FIFA, 2004.

6. Olympics News, December-January 1999.

7. Swiss Futsal Magazine, April 2004.

8. Soccer 1994.

9. SporTVision, No121/January 1998.

10. WORLD baseball, N3/1995.

11. WORLD HANDBALL magazine, 4/97, 3/2001. 


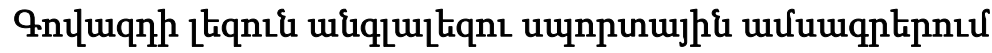

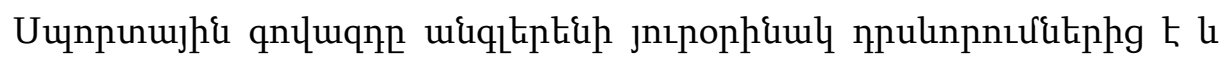

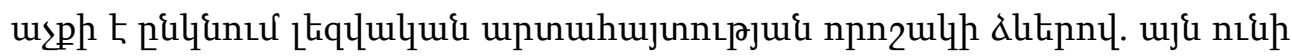

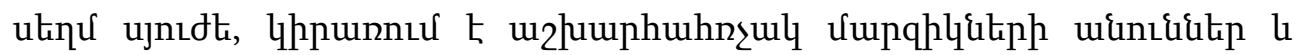

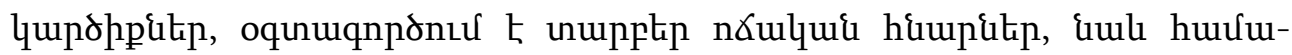

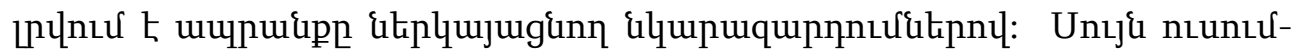

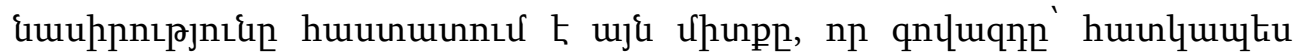

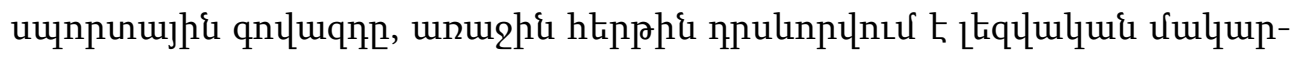

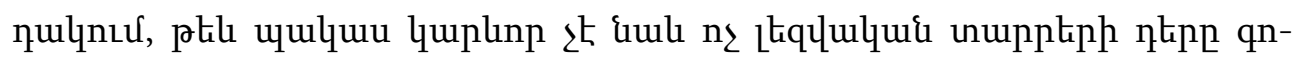

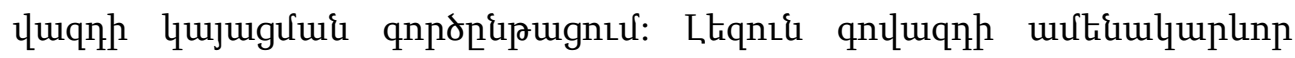
pununphs

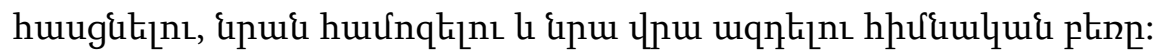

Received by Editorial Board 05.09.2019

Recommended for publication by Reviewers 25.10.2019

Accepted for Print 30.10.2019 